\title{
Acute mountain sickness in disability and adaptive sports: Preliminary data
}

\author{
Brad E. Dicianno, MD; ${ }^{1-5 *}$ Eric D. Aguila, MD; ${ }^{6}$ Rory A. Cooper, PhD; ${ }^{1-5}$ Paul F. Pasquina, MD; ${ }^{6}$ Mary J. \\ Clark, DO; ${ }^{7}$ Diane M. Collins, PhD, OTR/L; $;^{1,3,5}$ Shirley G. Fitzgerald, PhD; ${ }^{8}$ Todd A. Wichman, MD $^{6}$ \\ ${ }^{1}$ Human Engineering Research Laboratories, Departments of ${ }^{2}$ Physical Medicine and Rehabilitation, ${ }^{3}$ Rehabilitation Sci- \\ ence and Technology, and ${ }^{4}$ Bioengineering, University of Pittsburgh, Pittsburgh, PA; ${ }^{5}$ Department of Veterans Affairs (VA) \\ Pittsburgh Healthcare System, Center of Excellence in Wheelchairs and Related Technology, Pittsburgh, PA; ${ }^{6}$ Department \\ of Physical Medicine and Rehabilitation, Walter Reed Army Medical Center, Washington, DC; ${ }^{7}$ Grand Junction VA Medi- \\ cal Center, Grand Junction, CO; ${ }^{8}$ Patient Safety Center of Inquiry, James A. Haley Tampa VA Medical Center, Tampa, FL
}

\begin{abstract}
Acute mountain sickness (AMS) is a frequent complication for military personnel, veterans, athletes, and travelers at high altitudes. Symptoms may occur in individuals with less cerebrospinal fluid volume and less ability to accommodate increased brain volume. No studies on AMS exist in individuals with neurological impairments. We studied 64 subjects, including active and sedentary controls and those with tetraplegia, paraplegia, multiple sclerosis, and traumatic brain injury at the 2007 National Veterans Winter Sports Clinic in Snowmass, Colorado. Subjects completed three Lake Louise Score surveys to quantify symptoms. We found a higher than expected occurrence of AMS overall (51.6\%) but no differences among groups, and few participants sought treatment. Fatigue and weakness were common symptoms. High subject activity levels may explain these findings. More research is warranted on larger sample sizes and on preventative medications and treatments for AMS, especially since many military personnel with neurological impairments are returning to full active service.
\end{abstract}

Key words: altitude sickness, brain injuries, headache, military, multiple sclerosis, rehabilitation, spinal cord injuries, sports, veterans, visual impairment.

\section{INTRODUCTION}

Acute mountain sickness (AMS) is a frequent complication for military personnel, veterans, athletes, and travelers at high altitudes (HAs) and is the most common highaltitude illness (HAI) [1]. The occurrence of AMS depends on altitude but has been noted to be as high as 25 percent in Colorado, 53 percent in the Swiss Alps, and 77 percent at Mount Rainier [1]. Symptoms of AMS include headache, nausea, vomiting, fatigue, difficulty breathing, weakness, cold limbs, and concentration problems. Most research on AMS has been done on individuals without disabilities, and little is known about whether individuals with disabilities experience similar symptoms or have a similar occurrence of illness. Many military personnel with disabilities such as traumatic brain injury (TBI), spinal cord injury (SCI), and polytrauma are returning to full active service duty and being deployed to HA environments, flying in nonpressurized aircraft, and participating in HA sporting events as part of their rehabilitation. Hence, information on the likelihood of developing AMS and on

\footnotetext{
Abbreviations: AMS $=$ acute mountain sickness, AMS-C = cerebral AMS, ESQ = Environmental Symptoms Questionnaire, $\mathrm{HA}=$ high altitude, HAI = high altitude illness, LLS = Lake Louise Score, NSAID = nonsteroidal anti-inflammatory drug, NVWSC = National Veterans Winter Sports Clinic, $\mathrm{SCI}=$ spinal cord injury, TBI = traumatic brain injury.

*Address all correspondence to Brad E. Dicianno, MD; Human Engineering Research Laboratories, VA Pittsburgh Healthcare System, 7180 Highland Drive, Building 4, 2nd Floor East, 151R1-H, Pittsburgh, PA 15206; 412-365-4850; fax: 412-365-4858. Email: diciannob@herlpitt.org

DOI: 10.1682/JRRD.2007.08.0136
} 
what symptoms to expect is important for counseling and safety training of military personnel, for training medical staff, and for preparing strategies for prophylaxis and treatment.

At the 2007 National Veterans Winter Sports Clinic (NVWSC) in Snowmass, Colorado (elevation of 2,470 $3,813 \mathrm{~m}$ ) [2], over 350 athletes with TBI, SCI, stroke, visual impairments, amputations, and other disabilities participated in sports, such as downhill and cross-country skiing, pool scuba diving, sled hockey, snowmobiling, rock climbing, yoga, and shooting sports, for both recreation and rehabilitation. Many athletes at the NVWSC commonly complain of and seek treatment for symptoms of AMS. Sampson et al. reported the frequency of symptoms cited in 21 previous studies on AMS in those individuals without disabilities [3]. Symptoms were headache (95.2\%), nausea/vomiting (81.4\%), fatigue (71.4\%), difficulty breathing (66.7\%), dizziness/light-headedness (52.4\%), anorexia (47.6\%), rapid heart rate (42.9\%), insomnia (42.9\%), trouble concentrating (38.1\%), cold or cyanotic limbs (38.1\%), and limb or generalized weakness (33.3\%). Symptoms could also include other various changes in mood and cognition (up to 28.6\%), such as mental fatigue and impairments in vision, attention span, short-term memory, arithmetic ability, and decision making [4-5]. Edema can also occur in limbs [1]. In addition, sleep dysfunction, which has been documented in athletes at HAs [6], can complicate symptoms.

Known risk factors for HAI in individuals without disabilities include no exposure to HA in the preceding 2 months and ascent in $\leq 3$ days [5,7-8] as well as the altitude reached, the altitude at which the individual generally sleeps, and physical exertion at altitude [1]. However, independent risk factors for those with disabilities are still unknown.

Bartsch et al. presented a comprehensive summary on the pathophysiology of AMS and state of the science [7]. AMS may be due to damage to the blood-brain barrier and cerebral vasculature from free radicals. Little evidence has been found to suggest that cerebral edema or increased intracranial pressure is responsible for AMS, since these processes also occur in those individuals without symptoms [7,9]. However, some authors have suggested that individuals with less cerebrospinal fluid volume and thus less ability to accommodate for increased brain volume may be those who develop AMS [9]. Occurrence of more focal neurological symptoms in AMS is about 1 percent [10]. Evidence has not shown whether those with abnor- mal neurological pathophysiology, such as a history of TBI or SCI, may experience a higher occurrence of AMS or how to recognize symptoms that may differ from those of individuals without disabilities.

AMS is usually defined as a subjective experience of "feeling sick" within 4 days while one is exposed to altitude of at least 2,400 m, with other attributable illnesses ruled out [3,11]. Symptoms of AMS in individuals without disabilities can occur within 2 to 3 hours, especially if ascent is rapid, at more than $300 \mathrm{~m} / \mathrm{d}$ [7]. Symptoms generally resolve within 2 to 3 days [7]. Insomnia, however, may persist. Diagnosis depends on the presence of headache and at least one other symptom, such as nausea or vomiting, light-headedness or dizziness, or difficulty breathing or sleeping $[3,11]$. While no actual diagnostic laboratory test exists, the most widely used assessment is the Lake Louise Score (LLS) [11], a reliable and valid survey that is very easy to administer. The Environmental Symptoms Questionnaire (ESQ) [3] is another available survey [7]. The ESQ includes a subset of questions, the cerebral AMS (AMS-C), that is used to diagnose "cerebral" AMS. The ESQ can detect more severe stages of AMS, but it requires completion of other sections besides the AMS-C for ruling out other symptoms. These sections contain questions on bowel and bladder function, numbness, and thermoregulation, which may have limited utility in individuals with neurological impairments. In addition, the ESQ is less practical to use in a clinical setting because of the cumbersome calculations required.

No information on treatment of AMS in those with disabilities is available. The most effective treatment for AMS in individuals without disabilities is return to low altitude [5]. Oxygen may also be useful [5]. Aspirin, nonsteroidal anti-inflammatory drugs (NSAIDs), and acetaminophen can be used to treat headache [5]. Acetazolamide, which produces a metabolic acidosis and has diuretic effects, and dexamethasone, which has an unknown mechanism of action on AMS, are useful prophylactic agents [5,12].

Bartsch et al. have argued that more work is needed to determine which symptoms people exhibit, depending on their individual background and experience with altitude [7]. This study, therefore, was conducted to quantify the occurrence of AMS in a population of NVWSC athletes at HA.

The specific aim of this study was to compare the occurrence of AMS in a population of athletes with disabilities from neurological impairments with physically active 
and inactive control subjects at HA. We hypothesized that the occurrence and severity of AMS in individuals with disabilities from tetraplegia and TBI would be higher than that in both sedentary and physically active control subjects and other disability groups. Our rationale was that abnormal neurological pathophysiology may make some individuals more susceptible to the mechanisms that underlie the illness.

\section{METHODS}

This study was approved by the Department of Veterans Affairs Pittsburgh Healthcare System Institutional Review Board. We recruited registered athletes, trainers, and volunteers at the 2007 NVWSC registration exposition, medical staff meeting, and dining facilities. We established a research area that displayed information about the laboratories and the research being completed. Individuals who approached the booth or inquired about the research study and indicated an interest in participating were provided an informed consent document. After we obtained informed consent, we determined eligibility criteria. Inclusion criteria were as follows:

1. Subjects were between 18 and 80 years of age.

2. Physically active control subjects were trainers, volunteers, or individuals with visual impairments who were physically participating in sports activities and had no other apparent disabilities. (Many individuals participating as trainers or volunteers also participated in their own personal recreational exercise during the week of the clinic.)

3. Physically inactive control subjects were trainers, volunteers, or individuals with visual impairments who were not physically participating in sports activities and had no other apparent disabilities.

4. Case subjects were registered athletes who defined themselves as having any other physical disability or who used assistive technology, such as a wheelchair or prosthesis, for mobility or to assist with activities of daily living.

5. Subjects had to be able to provide written informed consent.

No exclusion criteria were given, since we wished to preserve external validity to veterans with comorbid medical conditions.

After we determined that the subjects met eligibility criteria, we asked subjects to complete a demographic and medical survey and our main outcome measure, a series of three LLSs on symptoms of AMS. Subjects completed the survey on the day of enrollment in the study and then again on each of the next 2 subsequent days (Table 1). Demographic variables included age, ethnicity, veteran status, home zip code or zip code at which patient had been sleeping in the last week, and gender. Medical variables included disability, past medical history, comorbid conditions, HAI and travel history, and prophylactic medication usage.

We defined basic criteria for AMS as scoring at least 3 on the LLS, presence of a headache, and at least one of the following symptoms: change in appetite, nausea, vomiting, fatigue, weakness, dizziness or light-headedness, or difficulty sleeping. We encouraged subjects to report only symptoms that were new or different from baseline. Any subject meeting criteria suggestive of a diagnosis of AMS was referred for medical evaluation. We defined mild, moderate, and severe AMS as LLS of 3, 4 to 5, and 6 or more, respectively, when basic criteria for AMS were met. In addition, we performed a retrospective chart review of medical charts of all individuals presenting to the onsite medical clinic to calculate the number of occurrences of AMS in all individuals at the clinic, recording the number of general visits, the number of visits that resulted in a diagnosis of AMS, and the disability type.

Table 1.

Lake Louise Score sheet.

\begin{tabular}{llc}
\hline \multicolumn{1}{c}{ Symptom } & \multicolumn{1}{c}{ Severity } \\
\hline Headache & No headache & 0 \\
& Mild headache & 1 \\
& Moderate headache & 2 \\
& Severe headache, incapacitating & 3 \\
Gastrointestinal Symptoms & None & 0 \\
& Poor appetite or nausea & 1 \\
& Moderate nausea and/or vomiting & 2 \\
Fatigue/Weakness & Severe nausea and/or vomiting & 3 \\
& Not tired or weak & 0 \\
& Mild fatigue/weakness & 1 \\
& Moderate fatigue/weakness & 2 \\
& Severe fatigue/weakness & 3 \\
Dizziness/Light-Headedness & Not dizzy & 0 \\
& Mild dizziness & 1 \\
& Moderate dizziness & 2 \\
& Severe dizziness, incapacitating & 3 \\
& Slept as well as usual & 0 \\
Difficulty Sleeping & Did not sleep as well as usual & 1 \\
& Woke many times, poor sleep & 2 \\
& Could not sleep at all & 3 \\
\hline \hline
\end{tabular}




\section{ANALYSES}

We divided the participants into six groups: (1) active control, (2) inactive control, (3) TBI, (4) paraplegia, (5) tetraplegia, and (6) multiple sclerosis. We calculated overall occurrence of AMS in our entire study population and in each group by calculating the number of subjects who met diagnostic criteria for AMS on at least one LLS. We calculated the occurrence of AMS for those seeking treatment by tallying clinical diagnoses made at the NVWSC medical treatment area. We determined base altitude from which subjects traveled by using a database of U.S. Census Bureau information that links zip codes to altitudes (<http://www.zipdatafiles.com $>$; TPS Products and Services, Inc; New Castle, California). We set all alpha levels to 0.05 a priori. Using SPSS (SPSS, Inc; Chicago, Illinois), we ran individual analysis of variance models with Bonferroni corrections or Kruskal-Wallis analyses to compare subject groups with respect to continuous demographic variables, such as age or home altitude. We used chi-square analysis or Fisher's exact test to compare groups with respect to ordinal or categorical demographic variables, such as gender or presence or absence of medical comorbidities. Because a series of surveys exists for each subject, we ran a Mixed Model Analysis using R software* to evaluate for differences among subject groups with respect to total AMS scores, using "subject" as the random effect and "subject group" as the fixed effect. Because we found a significant interaction between subject group and gender, we controlled for gender in the analyses.

Using an alpha level of 0.05, a medium effect size of 0.4 , six subject groups, three repeated survey scores, and a Pearson correlation among repeated measures of 0.5 , we estimated that a total sample size of 60 (10 for each group) would be sufficient to yield over 80 percent power.

With six subject groups and some groups with less than 10 subjects, we ran a secondary Mixed Model Analysis using $\mathrm{R}$ software to evaluate for differences between two groups (control subjects and all other disability groups) while controlling for gender.

\footnotetext{
${ }^{*} \mathrm{R}$ Software is a free software available under the terms of the Free Software Foundation's GNU General Public License. More information is available at $<$ http://www.r-project.org/>.
}

\section{RESULTS}

\section{Subjects}

Overall, 366 veterans participated in the 2007 NVWSC. A total of 47 (12.8\%) were female, and all were U.S. veterans. A total of 66 subjects expressed interest in this study. Two subjects did not complete the informed consent document, but the remaining 64 individuals agreed to participate in the study. Of these, 26 (40.6\%) were female, 47 (73.4\%) were U.S. veterans, and $39(60.9 \%)$ were registered as athletes at the 2007 NVWSC. Ethnic distribution was 40 (62.5\%) Caucasian, 12 (18.8\%) African American/Black, 3 (4.7\%) American Indian, 2 (3.1\%) Asian American, 2 (3.1\%) Hispanic, and 5 (7.8\%) other or more than one ethnicity. Tables 2 to 3 show the medical conditions of NVWSC participants overall and of this study's subjects, respectively.

All 64 subjects completed demographic surveys and the first LLS. A total of 63 (98.4\%) subjects returned the first two surveys, and 60 (93.8\%) subjects completed all three.

Subject groups differed with respect to gender ( $p=$ 0.005), but no significant differences were found with respect to other variables (Table 4). All subjects traveled to the NVWSC in less than 1 day, and most began participating in sporting events 24 hours after arrival.

\section{Analysis}

A total of 33 (51.6\%) subjects met LLS criteria for AMS, with 7 (10.9\%) who were diagnostic of severe illness. The AMS scores for the tetraplegia and inactive control groups were slightly higher than those of other groups but did not reach statistical significance $(p=0.55)$ (Table 5). When subjects were grouped as either controls or individuals with disabilities in a secondary analysis, occurrence rates were 46.2 and 55.3 percent, respectively.

Table 2.

Medical conditions of all 2007 National Veterans Winter Sports Clinic participants.

\begin{tabular}{lr}
\hline \multicolumn{1}{c}{ Medical Condition } & $\boldsymbol{n}^{*}$ \\
\hline Spinal Cord Injury & 144 \\
Amputation & 69 \\
Visual Impairment & 58 \\
Traumatic Brain Injury & 50 \\
Multiple Sclerosis & 36 \\
Stroke & 5 \\
Other Neurological Impairments & 12 \\
\hline *Several participants carried more than one diagnosis. & \\
\hline
\end{tabular}


Table 3.

Characteristics of subjects $(N=64)$ enrolled in study from 2007 National Veterans Winter Sports Clinic.

\begin{tabular}{|c|c|c|}
\hline Subject Group & Subject & Description \\
\hline \multirow[t]{16}{*}{ Active Control $(n=16)$} & 1 & $\begin{array}{l}\text { Athlete w/visual } \\
\text { impairment }\end{array}$ \\
\hline & 2 & Ski instructor \\
\hline & 3 & Ski instructor \\
\hline & 4 & Skier, staff person \\
\hline & 5 & Skier, staff person \\
\hline & 6 & Skier, staff person \\
\hline & 7 & Skier, staff person \\
\hline & 8 & Skier, staff person \\
\hline & 9 & Skier, staff person \\
\hline & 10 & Skier, staff person \\
\hline & 11 & Skier, staff person \\
\hline & 12 & Skier, staff person \\
\hline & 13 & Skier, staff person \\
\hline & 14 & Skier, staff person \\
\hline & 15 & Skier, staff person \\
\hline & 16 & Skier, staff person, runner \\
\hline \multirow[t]{10}{*}{ Inactive Control $(n=10)$} & 17 & Staff person \\
\hline & 18 & Staff person \\
\hline & 19 & Staff person \\
\hline & 20 & Staff person \\
\hline & 21 & Staff person \\
\hline & 22 & Staff person \\
\hline & 23 & Staff person \\
\hline & 24 & Volunteer \\
\hline & 25 & Volunteer \\
\hline & 26 & Volunteer \\
\hline \multirow[t]{8}{*}{ TBI $(n=8)$} & 27 & Blast injury \\
\hline & 28 & Blast injury \\
\hline & 29 & Blast injury \\
\hline & 30 & Blast injury \\
\hline & 31 & Blast injury \\
\hline & 32 & $\begin{array}{l}\text { Blast injury w/transtibial } \\
\text { amputation }\end{array}$ \\
\hline & 33 & $\begin{array}{l}\text { Blast injury w/transfemoral } \\
\text { amputation }\end{array}$ \\
\hline & 34 & $\begin{array}{l}\text { Blast injury w/visual } \\
\text { impairment }\end{array}$ \\
\hline \multirow[t]{6}{*}{ Tetraplegia $(n=6)$} & 35 & C4 Incomplete \\
\hline & 36 & C4 Incomplete \\
\hline & 37 & C4 Incomplete \\
\hline & 38 & C5 Incomplete \\
\hline & 39 & C5 Incomplete \\
\hline & 40 & C6 Incomplete \\
\hline
\end{tabular}

\begin{tabular}{|c|c|c|}
\hline Subject Group & Subject & Description \\
\hline \multicolumn{3}{|l|}{ (Continued) } \\
\hline \multirow[t]{19}{*}{ Paraplegia $(n=19)$} & 41 & T3 Incomplete \\
\hline & 42 & T4 Complete \\
\hline & 43 & T4 Incomplete \\
\hline & 44 & T4 Incomplete \\
\hline & 45 & T6 Complete \\
\hline & 46 & T7 Incomplete \\
\hline & 47 & T7 Incomplete \\
\hline & 48 & T9 Complete \\
\hline & 49 & T10 Complete \\
\hline & 50 & T10 Incomplete \\
\hline & 51 & T12 Complete \\
\hline & 52 & T12 Complete \\
\hline & 53 & T12 Incomplete \\
\hline & 54 & L1 Incomplete \\
\hline & 55 & $\begin{array}{l}\text { L1 Incomplete w/transfem- } \\
\text { oral amputation }\end{array}$ \\
\hline & 56 & L2 Incomplete \\
\hline & 57 & $\begin{array}{l}\text { L2 Incomplete } \\
\text { w/arachnoiditis }\end{array}$ \\
\hline & 58 & L4 Incomplete \\
\hline & 59 & $\begin{array}{c}\text { Guillain-Barré syndrome } \\
\text { w/complete paraplegia }\end{array}$ \\
\hline \multirow[t]{5}{*}{$\operatorname{MS}(n=5)$} & 60 & MS \\
\hline & 61 & MS \\
\hline & 62 & MS \\
\hline & 63 & MS \\
\hline & 64 & MS \\
\hline
\end{tabular}

After arrival at NVWSC, 14 subjects were diagnosed within 24 hours, and 7, 11, and 1 subjects were diagnosed on their second, third, and fourth day, respectively. For all subjects, symptoms began a median of 2 days after arrival (range 1-4) and lasted a median of 1 day (range 1-3). No significant differences were found in total AMS scores, occurrence, day of diagnosis, or length of symptoms among subject groups in the primary or secondary analyses.

Fatigue and weakness were the most commonly reported symptoms overall (Tables 6-7). Of those experiencing headache, only four subjects reported headaches aggravated by a particular activity, namely skiing and 
JRRD, Volume 45, Number 4, 2008

Table 4.

Subject group demographics and acute mountain sickness scores from 2007 National Veterans Winter Sports Clinic.

\begin{tabular}{|c|c|c|c|c|c|c|c|}
\hline Variable & $\begin{array}{l}\text { Active } \\
\text { Control } \\
(n=16)\end{array}$ & $\begin{array}{l}\text { Inactive } \\
\text { Control } \\
(n=10)\end{array}$ & $\begin{array}{c}\text { TBI } \\
(n=8)\end{array}$ & $\begin{array}{c}\text { Paraplegia } \\
(n=19)\end{array}$ & $\begin{array}{l}\text { Tetraplegia } \\
\qquad(n=6)\end{array}$ & $\begin{array}{c}\text { MS } \\
(n=5)\end{array}$ & $p$-Value \\
\hline Age, mean \pm SD (yr) & $49.9 \pm 8.9$ & $49.4 \pm 10.4$ & $41.4 \pm 16.0$ & $52.2 \pm 11.7$ & $48.3 \pm 12.0$ & $46.8 \pm 11.3$ & 0.37 \\
\hline Female, No. (\%) & $9(56.3)$ & $8(80.0)$ & $0(0.0)$ & $6(31.6)$ & $1(16.7)$ & $2(40.0)$ & 0.005 \\
\hline \multicolumn{8}{|l|}{ Past Medical History } \\
\hline Hypertension, No. (\%) & 3 (18.8) & $1(10.0)$ & $5(62.5)$ & $5(26.3)$ & $2(33.3)$ & $1(20.0)$ & 0.22 \\
\hline Hypercholesterolemia, No. (\%) & $2(12.5)$ & $3(30.0)$ & $3(37.5)$ & $6(31.6)$ & $1(16.7)$ & $1(20.0)$ & 0.73 \\
\hline Heart Disease, No. (\%) & 0 & 0 & 0 & $1(5.3)$ & $1(16.7)$ & 0 & 0.39 \\
\hline Autonomic Dysreflexia, No. (\%) & NA & NA & NA & NA & 0 & NA & $>0.99$ \\
\hline Peripheral Vascular Disease, No. (\%) & 0 & $1(10.0)$ & 0 & $1(5.3)$ & 0 & 0 & 0.85 \\
\hline Any HAI, No. (\%) & $4(25.0)$ & $4(40.0)$ & $1(12.5)$ & $7(36.8)$ & $1(16.7)$ & 0 & 0.23 \\
\hline Sought Treatment for HA, No. (\%) & 0 & $3(30.0)$ & $1(12.5)$ & $5(26.3)$ & $1(16.7)$ & 0 & 0.15 \\
\hline $\begin{array}{l}\text { Taking Prophylactic Medication, } \\
\text { No. (\%) }\end{array}$ & $1(20.0)$ & 1 & 0 & $1(5.3)$ & 0 & 0 & 0.80 \\
\hline Headaches at HA, No. (\%) & $9(56.3)$ & $7(70.0)$ & $2(25.0)$ & $10(52.6)$ & $2(33.3)$ & $2(40.0)$ & 0.47 \\
\hline Traveled to HA in Last 2 Mo, No. (\%) & $3(18.8)$ & $2(20.0)$ & $2(25.0)$ & $4(21.1)$ & 0 & $2(40.0)$ & 0.76 \\
\hline $\begin{array}{l}\text { Avg Times in Last Yr Traveled to HA, } \\
\text { Mean } \pm \text { SD (\%) }\end{array}$ & $0.7 \pm 1.1$ & $1.0 \pm 0.9$ & $0.9 \pm 2.1$ & $0.7 \pm 1.0$ & $0.3 \pm 0.5$ & $0.8 \pm 0.8$ & 0.85 \\
\hline Avg Home Altitude (m) & $586.6 \pm 655.0$ & $262.6 \pm 603.0$ & $296.1 \pm 593.6$ & $185.5 \pm 311.9$ & $75.6 \pm 40.0$ & $477.8 \pm 519.9$ & 0.08 \\
\hline
\end{tabular}

Table 5.

Average acute mountain sickness (AMS) statistics by subject group from 2007 National Veterans Winter Sports Clinic. No differences were found among subject groups with respect to total average AMS scores, number of cases diagnosed, duration of symptoms, severity, or day on which first survey commenced.

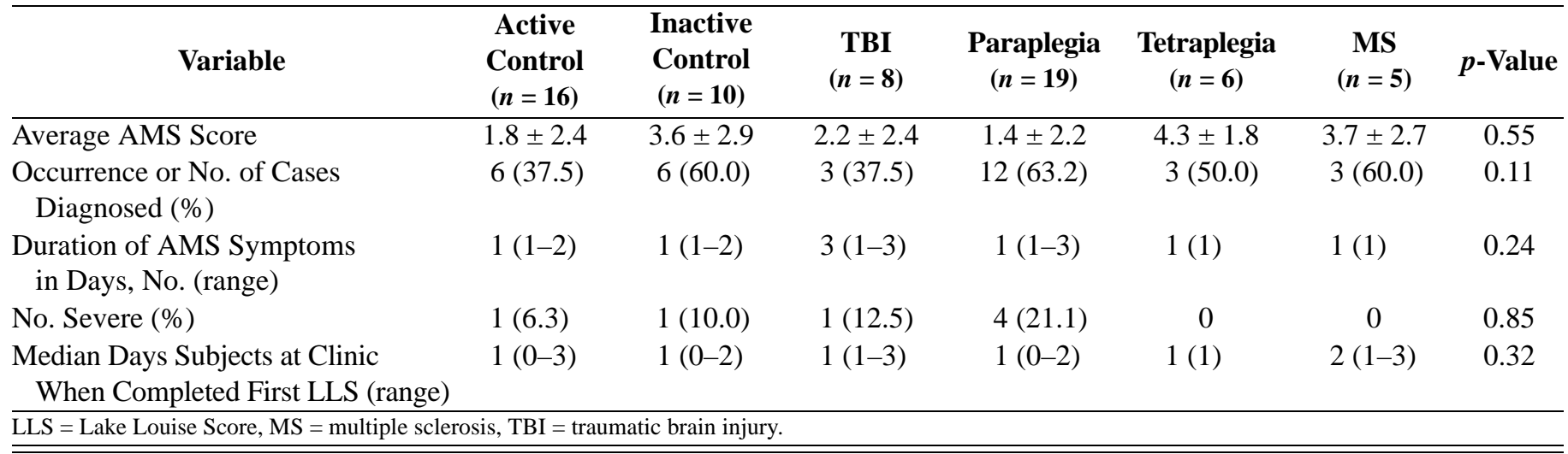

running (three active control subjects), and trapshooting and yoga (one subject with paraplegia). None of the subjects reported headaches while scuba diving at HA. Only three subjects reported using prophylactic agents-two used acetazolamide (active control and paraplegia) and one Gingko biloba (inactive control). One subject who reported using acetazolamide (active control) was diagnosed with AMS; the other two were not.

The 366 total athletes at the NVWSC visited the medical treatment area 175 times. Some athletes made two or more visits. No trainers or volunteers sought medical attention. Ten (5.7\%) of the athletes received a diagnosis of AMS. Diagnoses of those receiving treatment were SCI (three), visual impairment (three), cervical stenosis (two), TBI (one), and peripheral neuropathy (one). Medical staff treated patients with oxygen, hydration, aspirin, NSAIDs, and acetaminophen. No patients required return to low altitude or treatment with acetazolamide or dexamethasone. 
Table 6.

Number and percentage (\%) of subjects from 2007 National Veterans Winter Sports Clinic reporting acute mountain sickness symptoms in each category on several Lake Louise Score surveys.

\begin{tabular}{cccccc}
\hline Survey No. & Headache & $\begin{array}{c}\text { Gastrointestinal } \\
\text { Symptoms }\end{array}$ & $\begin{array}{c}\text { Fatigue/ } \\
\text { Weakness }\end{array}$ & $\begin{array}{c}\text { Dizziness/Light- } \\
\text { Headedness }\end{array}$ & $\begin{array}{c}\text { Difficulty } \\
\text { Sleeping }\end{array}$ \\
\hline 1 & $28(43.8)$ & $8(12.5)$ & $36(56.3)$ & $16(25.0)$ & $29(45.3)$ \\
2 & $26(40.6)$ & $8(12.5)$ & $35(54.7)$ & $12(18.8)$ & $30(46.9)$ \\
3 & $18(28.1)$ & $10(15.6)$ & $33(51.6)$ & $8(12.5)$ & $20(31.3)$ \\
\hline \hline
\end{tabular}

Table 7.

Number and percentage (\%) of acute mountain sickness symptoms organized by subject group from 2007 National Veterans Winter Sports Clinic.

\begin{tabular}{|c|c|c|c|c|c|c|}
\hline Symptom & $\begin{array}{l}\text { Active } \\
\text { Control }\end{array}$ & $\begin{array}{l}\text { Inactive } \\
\text { Control }\end{array}$ & TBI & Paraplegia & Tetraplegia & MS \\
\hline Headache & $4(25.0)$ & $1(10.0)$ & $4(44.4)$ & $8(44.4)$ & $2(33.3)$ & $1(20.0)$ \\
\hline Gastrointestinal Symptoms & $1(6.3)$ & 0 & $1(11.1)$ & $5(27.8)$ & 0 & 0 \\
\hline Fatigue/Weakness & $9(56.3)$ & $5(50.0)$ & $4(44.4)$ & $10(55.6)$ & $2(33.3)$ & $2(40.0)$ \\
\hline Dizziness/Light-Headedness & $3(18.8)$ & $2(20.0)$ & $1(11.1)$ & $1(5.6)$ & 0 & 0 \\
\hline Difficulty Sleeping & $8(50.1)$ & $4(40.0)$ & $4(44.4)$ & 12 (66.7) & 0 & $1(20.0)$ \\
\hline
\end{tabular}

\section{DISCUSSION}

We detected a much higher occurrence of AMS in all groups (37.5\%-63.2\%) than the 25 percent that is typical for Colorado [1]. At elevations of 2,500 to 3,500 m (HA), HAI is common, and at elevations of 3,500 to $5,800 \mathrm{~m}$, hypoxia during exercise commonly occurs along with HAI symptoms [1]. The occurrence may have been high in this study because many of the athletes competed in events that may have been more physically demanding than hiking, climbing, and trekking, which are the sports commonly studied in previous literature.

Estimates of the occurrence of clinically diagnosed AMS for different geographic regions depend on the number of individuals who seek treatment for symptoms. Despite over 50 percent of the subjects in this study meeting diagnostic criteria, few sought medical treatment even after prompting. Most likely, many individuals may think the symptoms are self-limiting or may try to self-treat. Most symptoms fell into the mild range and lasted on average 1 to 2 days. Indeed, if the occurrence of AMS in this study is extrapolated to the entire NVWSC population, we would expect that at least 180 individuals were symptomatic. Since only 10 visits resulted in a clinical diagnosis, possibly $<2$ percent of those with AMS symptoms sought treatment.

The majority of subjects did not have symptoms diagnostic of AMS until they had been at altitude for 48 hours, and most symptoms resolved in 2 days. Thus, the reported symptoms were not likely those that typically occur at lower altitudes that are related to neurological impairments. In fact, we specifically asked them to report only those symptoms that were different from baseline. In addition, symptoms were not likely purely due to travel itself. The LLS was validated for use in subjects who travel to HAs and requires a minimum score to be diagnostic.

A seemingly contradictory finding is the trend toward higher occurrence of AMS in inactive control subjects, although this was not statistically significant. Activity is a known risk factor for AMS [1]. An explanation for our results may be that the inactive control subjects, while not participating in exercise or sporting events while at HA, were more active than what they typically are at baseline, since they were volunteers and staff at the event. An alternate explanation is that many of the subjects in the active control group were skiers and, although no significant differences were found among groups with respect to home altitude or recent exposure, may have been slightly more acclimatized to HAs.

Another interesting finding is that although no significant differences were found among groups, the overall scores for those with tetraplegia trended toward being more severe. No subjects with tetraplegia had complete injuries or a history of autonomic dysreflexia. Inclusion of these types of subjects might have resulted in more reported symptoms. 
Those with paraplegia trended toward having a higher occurrence of AMS, but less severe symptoms. Many of the athletes with paraplegia participated in some of the most physically demanding sports at the NVWSC and more heavily relied on upper-limb muscle groups for strength and endurance, which can increase aerobic exertion and may have made some symptoms more prevalent.

An anecdotal finding in this study is that several participants who used service dogs noted that the dogs had limited endurance to assist with activities of daily living, and the participants subsequently required more human assistance than usual. No individual reported seeking veterinary care for a service dog. Although no research has been published on the topic of AMS for canines, Hackett reported anecdotal evidence that dogs can become afflicted with AMS, the symptoms of which include reduced appetite, listlessness, and reduced activity levels. ${ }^{*}$ Hackett further reported that a "mildly dusky" tongue color can indicate canine AMS. Increasing hydration and rest may alleviate canine symptoms.

\section{LIMITATIONS AND FUTURE DIRECTIONS}

Although we recruited an adequate sample size, subjects were unevenly distributed across groups, which may have limited the power of the study. In addition, since this was a survey study, subjects certainly could have overreported symptoms. However, the validated method of diagnosing AMS is using the LLS on subjective symptoms; thus one cannot assume that this would entirely explain the higher occurrence seen here.

Because NVWSC also involves social events, some individuals may have consumed alcoholic beverages that affected symptom reporting, and use of alcoholic beverages was not asked on the surveys. However, the majority of subjects began filling out surveys on the first day of the NVWSC, which was before many of the social events. Given that the occurrence of AMS was high on the initial surveys, the likelihood that alcohol influenced symptoms is less, at least initially. Some individuals with symptoms of AMS may not have sought treatment if they thought symptoms were due to alcohol, which may explain the low rate of presentation to the medical area. This study also did not

\footnotetext{
${ }^{*}$ Hackett PH. Altitude sickness. Available from:

$<$ http://traildog.hypermart.net/altitude sickness.htm>.
}

evaluate medications that subjects were actively taking. Possibly, medications for chronic pain, such as NSAIDs, diuretics, or antispasticity medications, could mask some symptoms of AMS, but given the overall occurrence found, this is unlikely. We plan to address medication and alcohol intake in future studies.

All the subjects with TBI had a history of blast exposure. Future studies should aim to recruit those with a history of skull fracture, craniotomy or craniectomy, or penetrating trauma. Occurrence of symptoms could possibly be higher in these subpopulations.

We also enrolled very few amputees or individuals with stroke in this study. This low enrollment was likely due to many amputees registering at an exposition booth that was distant from our recruitment area. Stroke also had low representation at the NVWSC overall. Given that HAI may be associated with cold or cyanotic limbs, edema, or limb weakness [1,3], further study is needed to identify symptoms in these groups. A more in-depth study is also needed for determining diagnostic criteria for AMS in amputees, given that the LLS does not contain detailed questions on limb symptoms. No amputees were treated for AMS at the 2007 NVWSC.

\section{CONCLUSIONS}

While no differences were found among subject groups with respect to occurrence of AMS or scores, this study shows that AMS in those with disabilities from neurological impairments is at least as high and as severe as in those without disabilities and that the most common symptoms are fatigue and weakness. The occurrence may be underestimated clinically because many do not seek treatment. More research is clearly needed on larger subject groups and on the role of prophylactic and treatment agents for AMS, particularly in those with neurological impairments.

\section{ACKNOWLEDGMENTS}

We would like to thank the medical staff of the 2007 NVWSC for their support and interest, Annmarie Kelleher and Emily Teodorski for their efforts in clinical coordination, and Christian Niyonkuru for help with statistical analysis. 
This material is the result of work supported by a donation from the Paralyzed Veterans of America Research and Education Foundation.

The authors have declared that no competing interests exist.

\section{REFERENCES}

1. Barry PW, Pollard AJ. Altitude illness. BMJ. 2003; 326(7395):915-19. [PMID: 12714473]

2. 2008 National Veterans Winter Sports Clinic [homepage on the Internet]. Washington (DC): Department of Veterans Affairs; c2008 [updated 2008 Apr 8; cited 2008 Jun 7]. Available from: http://www1.va.gov/vetevent/wsc/2008/default.cfm

3. Sampson JB, Cymerman A, Burse RL, Maher JT, Rock PB. Procedures for the measurement of acute mountain sickness. Aviat Space Environ Med. 1983;54(12 Pt 1): 1063-73. [PMID: 6661120]

4. Hossmann KA. The hypoxic brain. Insights from ischemia research. Adv Exp Med Biol. 1999;474:155-69. [PMID: 10635000]

5. West JB. The physiologic basis of high-altitude diseases. Ann Intern Med. 2004;141(10):789-800. [PMID: 15545679]

6. Kinsman TA, Gore CJ, Hahn AG, Hopkins WG, Hawley JA, McKenna MJ, Clark SA, Aughey RJ, Townsend NE,
Chow CM. Sleep in athletes undertaking protocols of exposure to nocturnal simulated altitude at $2650 \mathrm{~m}$. J Sci Med Sport. 2005;8(2):222-32. [PMID: 16075782]

7. Bartsch P, Bailey DM, Berger MM, Knauth M, Baumgartner RW. Acute mountain sickness: controversies and advances. High Alt Med Biol. 2004;5(2):110-24. [PMID: 15265333]

8. Schneider M, Bernasch D, Weymann J, Holle R, Bartsch P. Acute mountain sickness: influence of susceptibility, preexposure, and ascent rate. Med Sci Sports Exerc. 2002; 34(12): 1886-91. [PMID: 12471292]

9. Hackett PH. High altitude cerebral edema and acute mountain sickness. A pathophysiology update. Adv Exp Med Biol. 1999;474:23-45. [PMID: 10634991]

10. Macmillan AJF. Subatmospheric decompression sickness. In: Ernsting J, Nicholson AN, Rainford DJ, editors. Aviation medicine. London (England): Arnold; 2003. p. 19-25.

11. Roach RC, Bartsch P, Hackett PH, Oelz O. The Lake Louise acute mountain sickness scoring system. In: Sutton JR, Houston CS, Coates G, editors. Hypoxia and molecular medicine: Proceedings of the 8th International Hypoxia Symposium held at Lake Louise, Canada, 1993 Feb 9-13; Burlington (VT): Queen City Printers; 1993. p. 272-74.

12. Hackett PH, Roach RC. Medical therapy of altitude illness. Ann Emerg Med. 1987;16(9):980-86. [PMID: 3307558]

Submitted for publication August 31, 2007. Accepted in revised form December 28, 2007. 
